\title{
Distinguishing homogeneous from nanoparticle asymmetric iron catalysis
}

\author{
Jessica F. Sonnenberg and Robert H. Morris
}

Version Post-print/accepted manuscript

Citation Sonnenberg, J. F., \& Morris, R. H. (2014). Distinguishing homogeneous

(published version) from nanoparticle asymmetric iron catalysis. Catalysis Science \& Technology, 4(10), 3426-3438.

Additional Publisher The final published version of this article from the Royal Society of

Information Chemistry can be found at http://dx.doi.org/10.1039/C4CY00468J.

How to cite TSpace items

Always cite the published version, so the author(s) will receive recognition through services that track citation counts, e.g. Scopus. If you need to cite the page number of the author manuscript from TSpace because you cannot access the published version, then cite the TSpace version in addition to the published version using the permanent URI (handle) found on the record page.

This article was made openly accessible by $U$ of $T$ Faculty. Please tell us how this access benefits you. Your story matters. 


\section{Perspective: Distinguishing Homogeneous from Nanoparticle Asymmetric Iron Catalysis}

Jessica F. Sonnenberg and Robert H. Morris*

Department of Chemistry, University of Toronto, 80 St. George Street, Toronto, Ontario, M5S 3H6

Contact: Robert H. Morris, Robert.Morris@utoronto.ca

\section{Abstract}

This perspective will examine the use of a wide range of techniques for differentiating homogeneous from nanoparticle asymmetric catalysis as it pertains to two highly active systems developed within our group. The 6,5,6 and 5,5,5-precatalysts, trans-[Fe(NCMe) $\left.\mathrm{CO}\left(\mathrm{PPh}_{2} \mathrm{C}_{6} \mathrm{H}_{4} \mathrm{CH}=\mathrm{NCHPh}-\right)_{2}\right]\left[\mathrm{BF}_{4}\right]_{2}$ and trans$\left[\mathrm{Fe}(\mathrm{CO}) \mathrm{Br}\left(\mathrm{PR}_{2} \mathrm{CH}_{2} \mathrm{CH}=\mathrm{NCHPh}-\right)_{2}\right]\left[\mathrm{BPh}_{4}\right]$, respectively, are highly active and selective asymmetric transfer hydrogenation (ATH) catalysts. Here, we will review the series of tests that were undertaken to support that the 6,5,6-precatalyst forms iron nanoparticles (Fe NPs) during catalysis, whereas the 5,5,5-system remains homogeneous. Techniques include the use of NMR and DFT to investigate intermediates and activation steps, reaction profile and induction period analysis, substoichiometric poisoning, electron microscopy imaging, dynamic light scattering (DLS), X-ray photoelectron microscopy (XPS), magnetometry, and multiphasic analysis. We also elaborate on the wider applicability of these and other tests to probe the true nature of an active catalyst, with emphasis on the importance of using a wide range of techniques for insightful mechanistic evaluations.

\section{Table of Contents}

Overview Statement: We highlight the use of multiple techniques to differentiate homogeneous from nanoparticle catalysis as it pertains to systems developed in our group.

Graphic: 


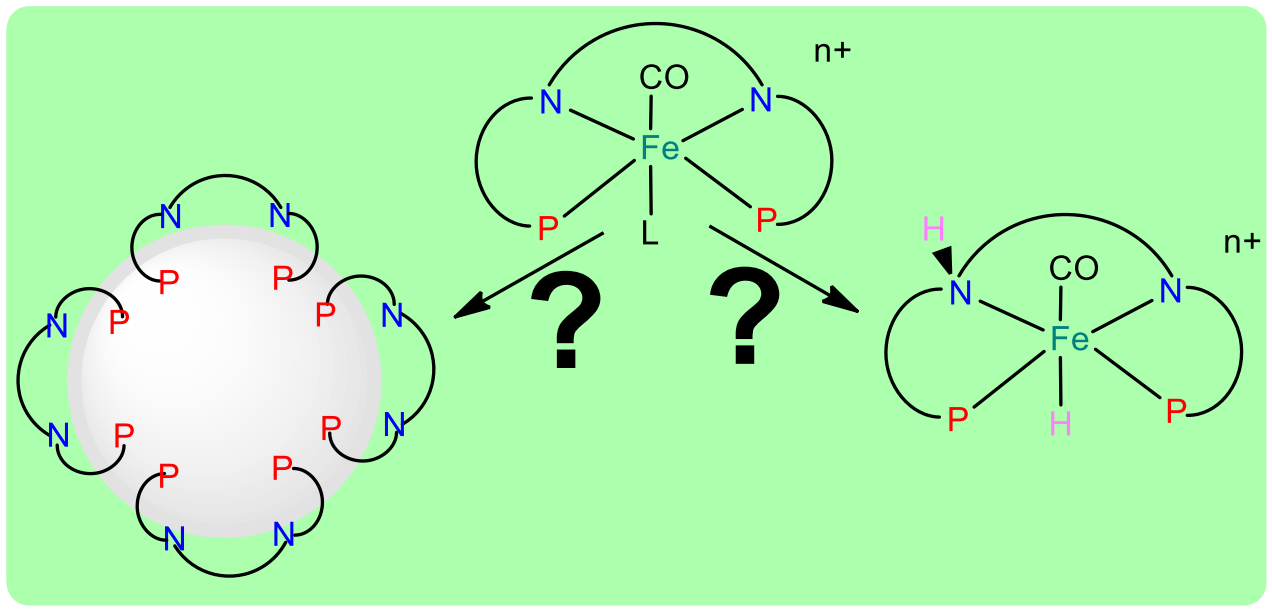

\section{Author Biographies}

\section{Jessica Sonnenberg}

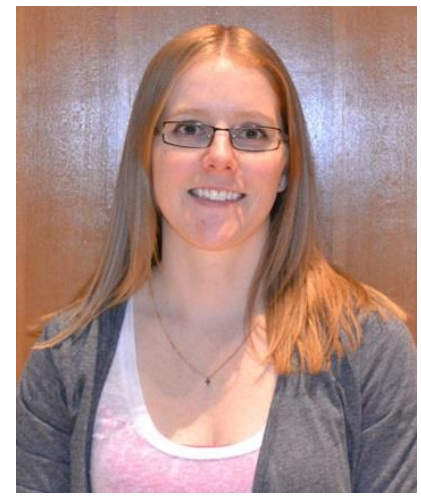

Jessica Sonnenberg grew up in Niagara Falls, Ontario and completed her undergraduate degree in 2010 from Queens University in Kingston, Ontario. While at Queens she studied the mechanism of titanium polymerization catalysts under the supervision of Dr. M. Baird. She then joined the research group of Dr. R. Morris at the University of Toronto for her PhD where she focused on mechanistic investigations of iron catalysts for hydrogenation and dehydrogenation reactions. She is currently completing her thesis. 


\section{Robert H. Morris}

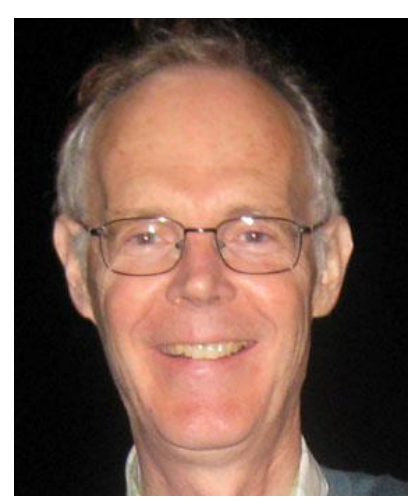

Bob Morris was born in Ottawa, Canada, in 1952. He received his PhD from the University of British Columbia in 1978 under the guidance of Prof. Brian James. After postdoctoral work at the Nitrogen Fixation Laboratory, University of Sussex and the Pennsylvania State University he joined the faculty of the University of Toronto in 1980. He was appointed full Professor there in 1989. He is a Fellow of the Chemical Institute of Canada and of the Royal Society of Canada. His research interests include the organometallic, bioinorganic and catalytic chemistry of transition metal complexes, with a focus on iron.

\section{The Importance of Identifying the True Catalyst}

What is the true nature of an active catalyst? Answering this question traditionally involved an investigation into whether a catalyst was homogeneous or bulk metal, but as nanoparticle catalysis becomes more prevalent this question becomes increasingly difficult and more important to answer. Determining whether a catalyst is homogeneous or heterogeneous is not straightforward, especially in the case of nanoparticle (NP) or cluster catalysis, and there is no single test that can conclusively prove what the true nature of a catalyst is. There have been several noteworthy reviews on how to distinguish homogeneous from heterogeneous catalysis, ${ }^{1-10}$ and here we will be focussing primarily on methods specific to soluble iron NPs and homogeneous iron catalysts developed within our group. Many conventional heterogeneous and nanoparticle catalysts are supported systems, and although very important and versatile, ${ }^{11}$ these will also not be the focus of this review. Critical to this field is the work of Finke, who's 2003 and 2014 reviews, and ground-breaking 1994 article, suggested using a suite of tests and experiments, that each provide evidence for heterogeneity or homogeneity which, when combined together, provide more valuable insights. ${ }^{1,3,4}$ In his 2003 review he refers to the suite of potential tests as the 'toolkit', and we will focus on reviewing, further expanding, and adding to this toolkit as it pertains to 
our own catalytic systems. It is also important to address the advice detailed by Platt in his 1964 article entitled 'Strong Inference' where he details the importance of disproof based science. ${ }^{12}$ In his article he discusses the importance of devising alternative hypotheses, and executing experiments to test these alternative hypotheses, followed by repeating this process (asking, 'what test could disprove your hypothesis?'). This disproof based experimentation and problem solving must be applied to answering the title question, whereby a series of tests must be undertaken, each guiding the next, much like a knowledge tree, to build a fact-based assessment of the catalyst mechanism. The application of this methodology has been recently detailed extensively as it applies to the question of homogeneity versus heterogeneity for water oxidation catalysts with polyoxometalate systems by Stracke and Finke. ${ }^{4}$

It is important to first consider why such a strong emphasis has been placed on determining the true nature of a catalytic system. It is only through a complete understanding of the catalytic mechanism that we can start to make significant improvements to catalytic activity, recyclability, selectivity and stability. For NP systems, reaction conditions such as temperature, concentration, pressure and the nature of the reagents, as well as the synthetic methods used to generate the NPs (type of reductants, solvents, time, temperature, pressure, concentration, etc.) can all affect the size, shape, morphology, crystallinity and dispersity of the NPs. ${ }^{13,14}$ The type, binding nature and concentration of stabilizers or ligands can also have a large influence on the NP structure and behaviour. ${ }^{11,13,15-17}$ All of these factors will, in turn, affect the catalyst's performance. ${ }^{10}$ For NPs, many of these factors can be sequentially modified to properly tailor the catalyst to better suit the desired catalytic application, making it critical to first understand how the catalyst operates. Homogeneous systems, much like NPs, are strongly influenced by their environments, and therefore understanding the mechanism and energies of transition states can allow for rational modifications to the catalyst structure or reaction conditions for improved performance. This type of sequential modification and analysis methodology has been recently used by our group for a homogeneous asymmetric transfer hydrogenation (TH) catalyst which is now the most efficient catalyst in its field. ${ }^{18-20}$ This process would not have been successful without first determining the true nature of the catalyst, and by understanding the structure, energetics and behaviour of the active site in the catalytic environment, further improvements to the precatalyst structure were rationally made. For further details, the importance of distinguishing homogeneous from heterogeneous catalysis is reviewed elsewhere. ${ }^{1,2,4}$ 


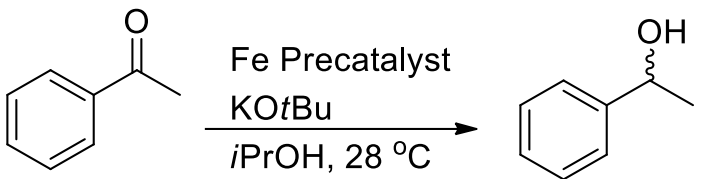

Scheme 1: Transfer Hydrogenation (TH) of acetophenone to 1-phenylethanol.

We first became interested in this question of heterogeneity versus homogeneity when we were investigating the mechanism of two of our iron transfer hydrogenation (TH) (Scheme 1) catalysts, the 6,5,6 and $5,5,5$-systems, trans-[Fe(NCMe) $\left.\mathrm{CO}\left(\mathrm{PPh}_{2} \mathrm{C}_{6} \mathrm{H}_{4} \mathrm{CH}=\mathrm{NCHPh}-\right)_{2}\right]\left[\mathrm{BF}_{4}\right]_{2}$ and trans$\left[\mathrm{Fe}(\mathrm{CO}) \mathrm{Br}\left(\mathrm{PR}_{2} \mathrm{CH}_{2} \mathrm{CH}=\mathrm{NCHPh}-\right)_{2}\right]\left[\mathrm{BF}_{4}\right]$, respectively, both shown at the top of Scheme 2 . The $6,5,6$ and 5,5,5 notations refer to the ring sizes of the corresponding Fe-(P-N-N-P) systems, depicted in red in Scheme 2. We began investigating the use of tetradentate P-N-N-P ligands on iron following the successful synthesis of the 6,5,6-(P-N-N-P) ligands of Jeffery et al. ${ }^{21}$ and their corresponding ruthenium compounds by Gao et. al. ${ }^{22-24}$ They were able to modify the chirality of the ligand using a wide range of commercially available chiral diamines, and they could generate both the diimine and diamine $\mathrm{P}-\mathrm{N}-\mathrm{N}-\mathrm{P}$ and $\mathrm{P}-\mathrm{NH}-\mathrm{NH}-\mathrm{P}$ systems, respectively, by $\mathrm{NaBH}_{4}$ reduction. The ruthenium systems with the diamine backbone were shown to be fairly active and selective for the TH of ketones to chiral alcohols, where the diimine system was inactive. Exploration of iron catalysts for the hydrogenation of ketones first began with work by Jothimony et al. ${ }^{25,26}$ whose catalytic systems were small iron carbonyl cluster compounds. Gao et al. ${ }^{27}$ found that adding a tetradentate ligand $(S, S)-\mathrm{PPh}_{2} \mathrm{C}_{6} \mathrm{H}_{4} \mathrm{CH}_{2} \mathrm{NHC}_{6} \mathrm{H}_{10} \mathrm{NHCH}_{2} \mathrm{C}_{6} \mathrm{H}_{4} \mathrm{PPh}_{2}$ to the iron(0) carbonyl cluster $\left[\mathrm{NEt}_{3} \mathrm{H}\right]\left[\mathrm{Fe}_{3} \mathrm{H}(\mathrm{CO})_{11}\right]$ resulted in a system for the asymmetric TH of ketones. Following their success, we were interested in testing the effectiveness of P-N-N-P ligands on iron, and successfully synthesized and tested a series of $[\mathrm{Fe}(\mathrm{P}-\mathrm{N}-\mathrm{N}-\mathrm{P})(\mathrm{NCMe}) \mathrm{L}]^{2+}(\mathrm{L}=\mathrm{NCMe}$ or $\mathrm{CO})$ complexes for both direct hydrogenation $(\mathrm{L}=$ $\mathrm{NCMe})$ and TH $(\mathrm{L}=\mathrm{CO}) \cdot{ }^{28-30}$ The 6,5,6-system shown in Scheme 2 (left) with the diphenylethylene diimine backbone achieved turnover frequencies (TOF) of up to $2600 \mathrm{~h}^{-1}$ and enantioselectivities of $65 \%$ for the $\mathrm{TH}$ of acetophenone to 1-phenylethanol. ${ }^{30}$ To improve these results, we designed a new series, or second generation, of iron catalysts with a smaller chelating ring that would allow for more modifications to be made. The 5,5,5-systems, shown in Scheme 2 (top right), are formed using phosphonium dimers, ${ }^{18}$ which allows for extensive modification of the phosphorous substituents, including both alkyl $\left.\right|^{31}$ and aryl groups. ${ }^{32}$ These systems proved to be exceptionally active, yielding TOFs of up to $30,000 \mathrm{~h}^{-1}$ and enantioselectivities up to $90 \%$ for acetophenone. ${ }^{32}$ Given the successful catalysis with both generations of precatalysts, we set out to determine the catalyst mechanism in the hopes of being able to generate even more active and selective systems. 
First Generation $(6,5,6)$

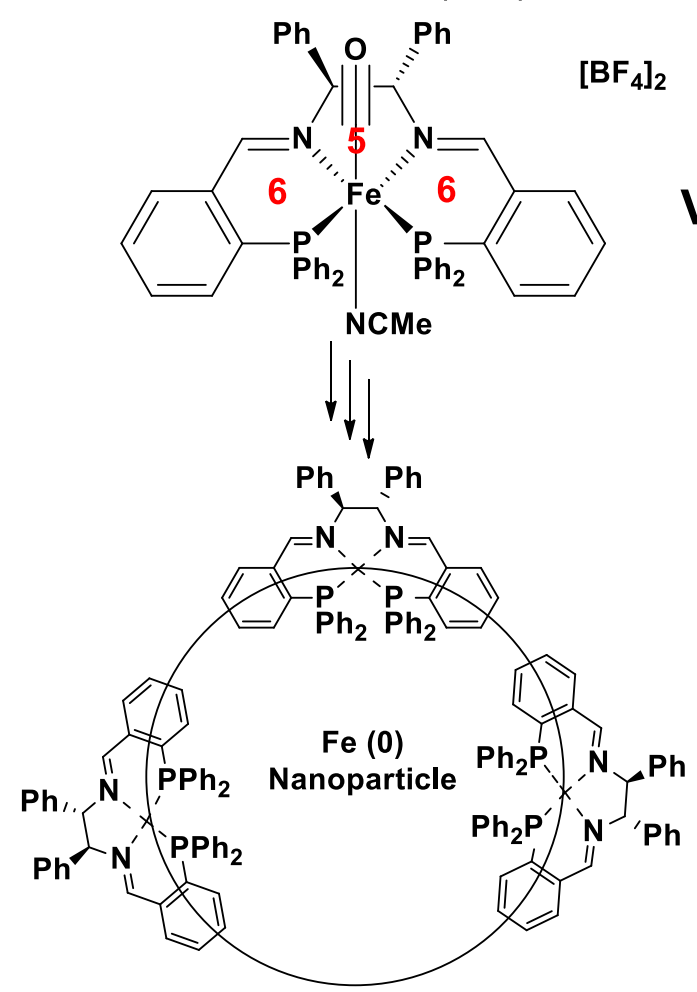

Second Generation $(5,5,5)$
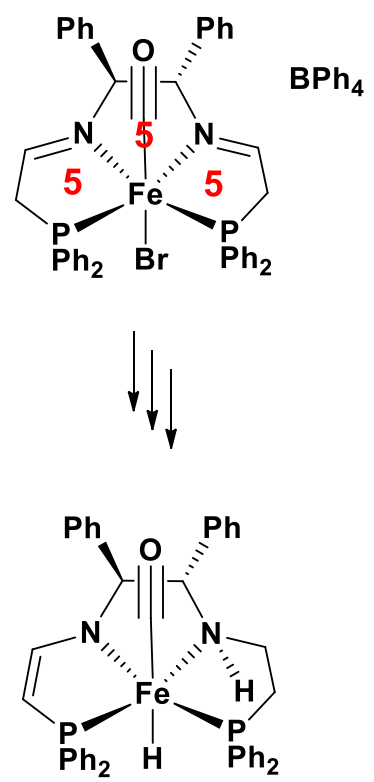

Scheme 2: Iron-PNNP transfer hydrogenation catalysts developed by our group. Left: First Generation, 6,5,6-system and proposed formation of active species. Right: Second Generation, 5,5,5-system and proposed formation of active species.

\section{NMR and DFT Experiments}

When we first began our investigation, we assumed both generations would follow the same general mechanism of activation and catalytic turnover, and therefore set about probing both simultaneously. At the time, there were no reports in the literature of asymmetric catalysis on a Fe NP surface, and we therefore began our studies using techniques traditionally employed for homogeneous catalysis, namely NMR and computational (DFT) studies. ${ }^{33}$ Conveniently, our systems have a phosphorus containing ligand, which enabled the use of ${ }^{31} \mathrm{P}$ NMR. Analysis of the 6,5,6-system indicated the presence of free ligand, showing that some ligand had become de-coordinated from iron during activation. The other compound present in the ${ }^{31} \mathrm{P}$ NMR spectrum was identified as an electron rich ferraaziridine complex where one side of the ligand arm folded to coordinate to the metal centre. ${ }^{33}$ Initially, we assumed that this ferraaziridine complex was the active species, so it was independently synthesized and tested for catalysis, but found to be inactive. This indicated that our true active species was NMR silent, and rigorous computational studies were undertaken to determine the role of the ferraaziridine complex in catalysis. DFT indicated that it was an intermediate to a stable zero-valent Fe-(P-N-N-P) species, providing a potential pathway to 
NP formation. Using DFT we also studied the 5,5,5-system and determined that the folding mechanism was energetically unlikely due to the rigidity of the ligand scaffold. Instead, low energy pathways were determined for the reduction of the ligand to form amides, followed by stepwise proton and hydride transfers to generate the active, postulated $\mathrm{NH}-\mathrm{FeH}$ species, ${ }^{34}$ as shown in Scheme 2 (bottom right). This ligand flexibility in the 6,5,6 and rigidity in the 5,5,5-systems explains why the systems activate in such different ways, as will be discussed in more detail below. The 6,5,6 example illustrates the importance of independently synthesizing and testing potential intermediates determined by NMR, and demonstrates the power of combining multiple techniques to determine an activation mechanism.

No longer only useful for characterizing starting materials and metal precursors, NMR is one of the most powerful tools for garnering mechanistic insights and identifying reactive intermediates in catalysis. NMR has been used extensively in homogeneous catalysis to identify and characterize reactive intermediates, commonly metal hydrides, fluxional species and isotopically enriched intermediates. ${ }^{20,35-41}$ Although the use of NMR to determine the mechanism of homogeneous catalysis is enormous, the use of NMR to study NP systems is fairly limited. Many catalytically active NP solutions contain paramagnetic and superparamagnetic species which can complicate NMR analysis for heterogeneous systems, but a messy NMR is by no means evidence for NP catalysis. NMR is a powerful technique that allows for the sequential analysis of a large number of different nuclei that may be present in the NP itself, or in the ligand, for example ${ }^{31} \mathrm{P},{ }^{29} \mathrm{Si},{ }^{10} \mathrm{~B},{ }^{19} \mathrm{~F},{ }^{7} \mathrm{Li}$ and ${ }^{195} \mathrm{Pt} \mathrm{NMR} .{ }^{4}$

Another application of NMR for NP catalysis is the use of solid state NMR as shown by Chaudret et. al. to probe the surface chemistry and reactivity of ruthenium NPs. ${ }^{42,43}$ Using $2 \mathrm{~nm}$ Ru NPs formed in the presence of polymer (polyvinylpyrrolidone - PVP) or ligand (bis-(diphenylphosphino)butane - dppb), the location and dynamics of ${ }^{13} \mathrm{CO}$ on the surface of the particles could be directly monitored in the solid state using magic-angle spinning (MAS) ${ }^{13} \mathrm{C}$ NMR. Using the NMR data, they were able to determine the location (face, edge or vertex) of the $\mathrm{CO}$ as well as its bonding geometry (bridging or linear) as a function of the type of ligand/stabilizer and CO exposure conditions. ${ }^{42}$ Chaudret et. al. then took this one step further and characterized $\mathrm{N}$-heterocyclic carbene $(\mathrm{NHC})$ stabilized Ru NPs, and were similarly able to determine location and dynamics of CO, NHC and hydride ligands on the surface as a function of NHC sterics, as depicted in Figure 1. These results were then analysed in conjunction with catalytic behaviour, allowing for in depth mechanistic information to be determined correlating ligand sterics with surface/active site effects and catalytic activity. ${ }^{43}$ 

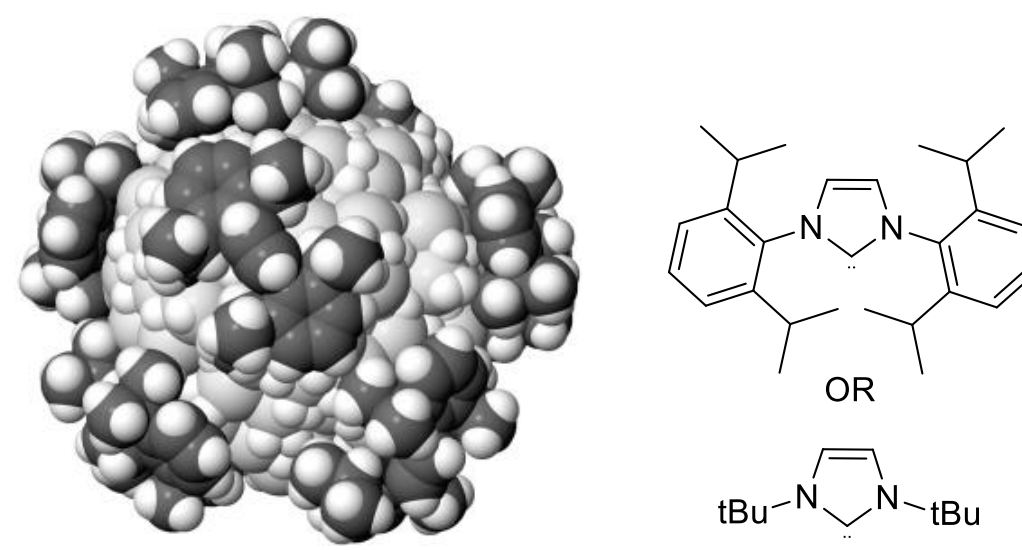

Figure 1: Space filling model depicting Ru NPs selectively coated by NHC ligands as determined by ${ }^{13} \mathrm{C}$ solid state NMR. Two NHC ligands tested are also shown for clarity. Reprinted with permission of Reference 43. Copyright 2011 Wiley-VCH.

\section{Reaction Profile and Kinetic Analysis}

Given that the active species for our 6,5,6-system may be derived from zero-valent iron, a more detailed mechanistic investigation was undertaken to probe whether the true catalyst could be heterogeneous iron nanoparticles (Fe NPs). ${ }^{44}$ We began by investigating the reaction profile for both the $6,5,6$ and 5,5,5systems, and the reaction kinetics, as it is well reported that kinetic investigations are paramount to accurate identification of a NP system. ${ }^{4,45-47}$

For the 6,5,6-system, the reaction profile was sigmoidal in shape; the induction period was found to be due to the reaction of the precatalyst with base, followed by rapid catalytic activity and eventual equilibration ( $\mathrm{TH}$ is an equilibrium process). To probe the base dependence we reacted the precatalyst with base in $\mathrm{iPrOH}$ for 10 minutes prior to the addition of substrate, and observed a significantly diminished induction period. ${ }^{44}$ This suggests that the reaction of the precatalyst with base is responsible for the induction period, which forms Fe (0) complexes, as indicated by NMR and DFT analysis. ${ }^{33}$ For the 5,5,5-system, initial investigations into the role of base showed that a highly reactive bis-ene-amido species could be isolated, and that this species could be used directly in catalysis without base. ${ }^{36}$ An interesting curiosity was the presence of an induction period and sigmoidal reaction profile with the 5,5,5systems. The isolated bis-ene-amido species (after treatment with base), however, exhibited no induction period when use directly in catalysis. ${ }^{36}$ This suggests that unlike the 6,5,6-system where the induction period and role of base were likely to reduce the metal centre to iron NPs, the 5,5,5-system's induction period was due to the formation of this reactive intermediate. Detailed kinetic studies on the activation and catalytic activity of the 5,5,5-system provided valuable insights into the mechanism of the system 
which were supported by DFT calculations previously discussed. ${ }^{19,34}$ It was determined that activation was dependent on catalyst and base concentrations and inversely dependent on substrate concentration. Catalysis, on the other hand, was not dependent on base concentration; once the catalyst becomes activated by base in isopropanol, additional base is no longer needed. The inverse dependence on the substrate acetophenone was explained by the formation of an enolate which binds to the iron centre, slowing activation. Kinetic profiles were also successfully and accurately simulated using experimentally determined rate constants and equations, all of which supported a homogeneous mechanism. ${ }^{19}$ An important discovery in the study of the 5,5,5-system was the isolation of an amide-amine iron species upon quenching the bis-ene-amido species with $\mathrm{HCl}$. This species, shown in Figure $2 \mathrm{~b}$, was shown to catalyse TH with a TOF of $50,000 \mathrm{~h}^{-1}$, nearly double the rate of the original 5,5,5-precatalyst, in the presence of base. This eventually led to the development of our third generation catalyst, capable of achieving TOFs up to $200 \mathrm{~s}^{-1} \cdot{ }^{20}$ Returning to this concept of catalytic quenching using acid followed by reactivation with base, we applied this concept to our 6,5,6-system as a final test that the two systems behaved differently mechanistically. Both systems were individually activated using base in isopropanol in the presence of substrate, and allowed to react to $~ 15 \%$ conversion before an excess of $\mathrm{HCl}$ was added to quench the reaction. This was then allowed to stir for a short period of time before a fresh batch of base (KOtBu) was added to reactivate the solution. The conversion of acetophenone to product was monitored throughout the process, as depicted in Figure 2. Upon the addition of $\mathrm{HCl}$, both systems deactivate, indicated by the lack of conversion. After the addition of further base, only the 5,5,5-system regains its activity, whereas the 6,5,6-system cannot be reactivated. This test provided strong evidence that the two systems, although structurally quite similar, were in fact completely different. 

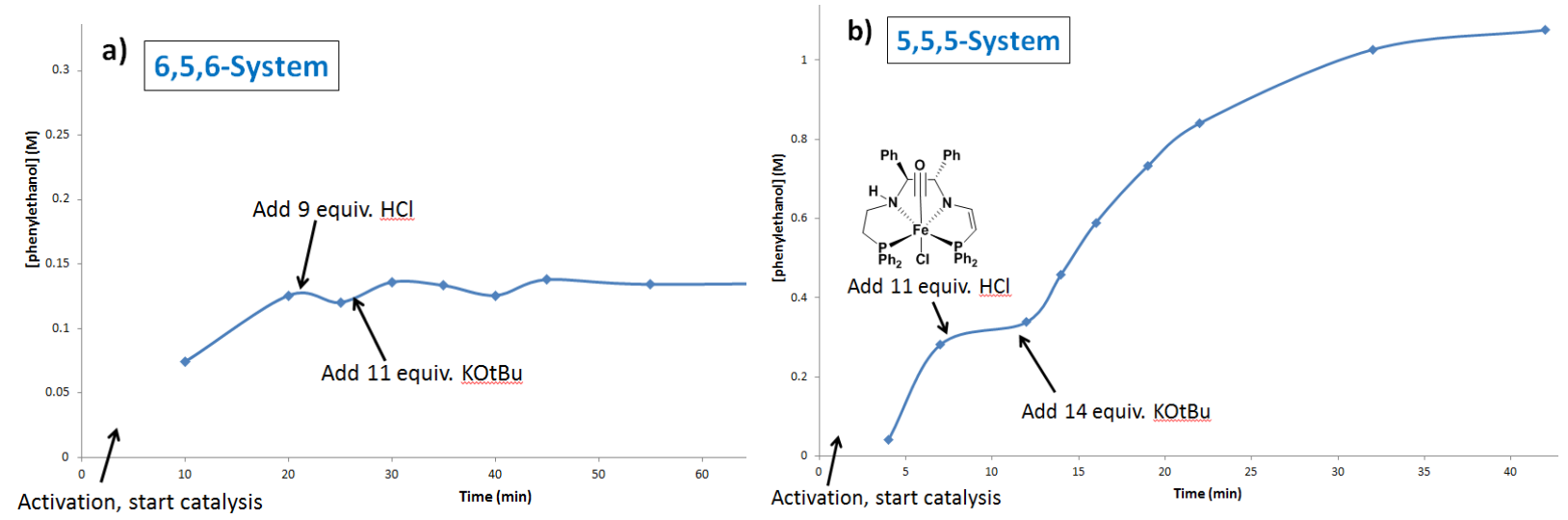

Figure 2: Reaction profiles for the conversion of acetophenone to 1-phenylethanol over time using the 6,5,6-system (a) and the 5,5,5-system (b). Plots depict the effect of adding $\mathrm{HCl}$ following by reactivation with KOtBu. Adapted with permission from Reference 44. Copyright 2012 American Chemical Society.

Kinetic studies and reaction profile analysis are considered some of the most powerful in operando techniques for determining the true nature of a catalytic system. ${ }^{1,3,4}$ They allow the catalyst to be observed in its 'natural habitat', and are required for a complete analysis of any catalytic system. It is well reported that one of the most common preliminary identifiers of NP catalysis come from directly monitoring the reaction. A dark or non-transparent reaction solution is suggestive of zero-valent metal centres and colloidal suspensions which are often generated under strongly reducing reaction conditions, such as the presence of strong base, reductants, and hydrogen gas. ${ }^{1}$ Dark or non-transparent solutions by no means prove NP formation, but the observation of a resultant dark solution should prompt further investigations into the true nature of the system.

Next and arguably most importantly, is the characteristic sigmoidal reaction curve, as depicted in Figure 3 , and the reaction kinetics that give rise to the curve. The three main sections of the curve are 1) initiation, 2) catalysis and 3) completion. Initiation refers to the formation of the active sites, and this process has been studied in detail by Finke and co-workers, who suggest that to truly understand how a catalyst operates, one must study the kinetics in detail to determine the rate law, including running all relevant control experiments, to fully understand where the precatalyst mass goes. ${ }^{4,45,48-50}$ Depending on the mechanism of catalyst activation, this initiation phase can encompass a wide range of transformations, often including some kind of nucleation and growth phase, although the process is exceptionally more complex and must often be studied on a case-by-case basis. The size of the final, active nanoclusters can also be predicted based on low energy conformations containing specific numbers of metal atoms, or 'magic numbers' ${ }^{49,51}$ Following the formation of the active species is phase 2, rapid catalytic activity, 
followed by the completion of the reaction (phase 3). A thorough kinetic investigation, if done correctly, can provide strong evidence for nanoparticle catalysis, however this is not always feasible depending on the catalytic system under investigation. For our 6,5,6-system, due to how air sensitive and fast reacting the system was, as well as the fact that several side reactions were taking place yielding inactive and partially unidentified species, we were not able to monitor the consumption of precatalyst mass during the reaction. ${ }^{44}$ This prevented a detailed kinetic investigation of the activation of our system, inhibiting effective modelling of NP formation and catalysis. To fully understand the intricacies of catalyst formation, kinetic studies to determine the rate constants and product formation are crucial, and this has been studied in detail by Finke and co-workers, and we direct any interested reader to their work. ${ }^{1,3,4,45-49}$ To give an example of the power of kinetic analysis, using the Finke-Watzky (F-W) Kinetic model, which they derived for their system, Finke et. al. were able to accurately predict reaction profiles based on rate constants and equations specific to NP nucleation and growth, as depicted in Figure $3 .{ }^{45,50}$

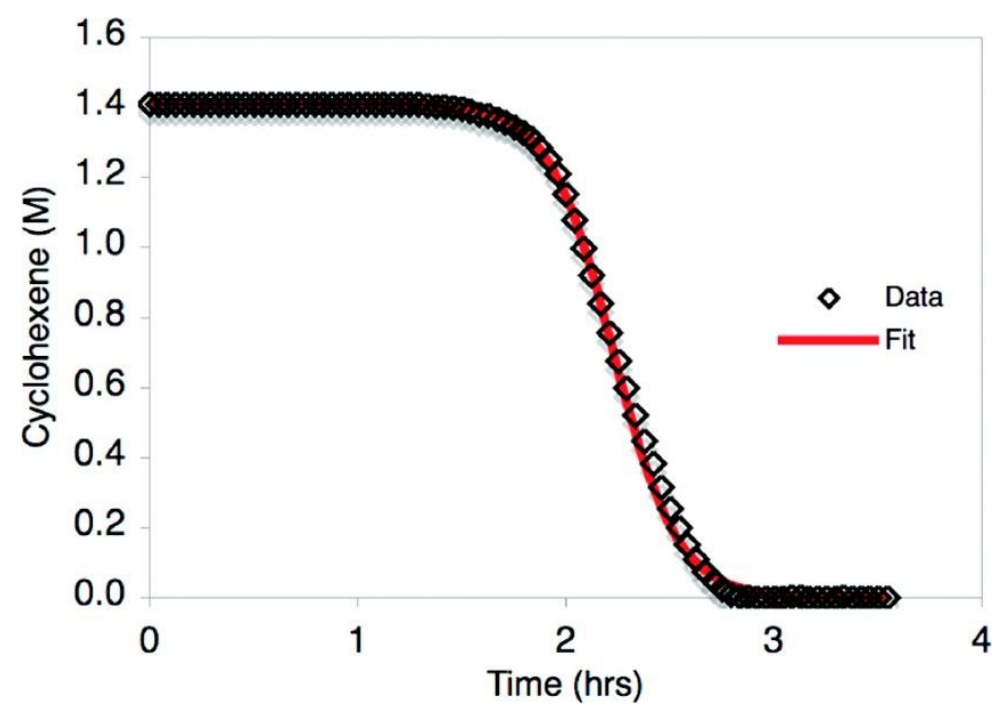

Figure 3: Sigmoidal reaction curve depicting the hydrogenation of cyclohexene over time (plot of cyclohexane formation over time would result in the standard sigmoidal curve). Curve shows all three phases: initiation, catalysis and completion. Also shown is the predicted curve using F-W Kinetics. Reprinted with permission from Reference 50. Copyright 2009 American Chemical Society.

\section{Poisoning Experiments}

Returning to the problem of differentiating our two Fe catalysts, the 6,5,6 and 5,5,5-systems, and determining their true catalytic nature, we next turned our attention to the use of poisoning agents. Following sigmoidal reaction profile analysis and kinetic investigation, the next most important test for a 
NP catalyst is poisoning. There are two main types of poisoning tests commonly employed: substoichiometric and mercury. Both tests are considered in operando techniques as they allow for the direct monitoring or analysis of the system while it is catalytically active.

The first type of NP poisoning test involves the use of substoichiometric amounts of small poisoning agents such as phosphines, thiols, amines and alcohols. ${ }^{1-3,52}$ For a homogeneous catalyst system, one would expect to need one or more equivalents of poison to inhibit catalysis (every metal centre represents an active site). In a NP system, much of the metal introduced as the precatalyst forms the core of the active species, whereas the remaining metal makes up the reactive NP surface, resulting in proportionately fewer active sites. This would indicate that much less than one equivalent of poison (relative to metal) is needed to inhibit NP catalysis. The difficulty with this technique is choosing the correct poison that will bind to and block the active sites of the catalyst, keeping in mind the issue of stoichiometry (can a single poison block more than one active site?). ${ }^{3,53}$ This method of testing is widely used and studied and so we would like to first detail its applicability to our iron systems, then discuss its applicability in a related iron system developed by Vance et. al. ${ }^{54}$

We began by investigating our suspicious, 6,5,6-system for NP behaviour using small phosphine containing ligands. While conducting our poisoning experiments we discovered an interesting correlation between the electronics and sterics of the poisons tested, and their ability to inhibit catalysis, as depicted in Figure $4 .{ }^{44}$ We found that catalysis was completely stopped after the introduction of only $10 \%$ (relative to Fe) $\mathrm{PMe}_{3}$ or $\mathrm{PPhMe}_{2}$, whereas $20 \% \mathrm{P}(\mathrm{OMe})_{3}$ was needed to significantly slow down catalysis, providing evidence that the active species was in fact Fe NPs. Poisons were added after the induction period ( 8 minutes) to ensure that all of the catalyst was activated. Interestingly, small amine poisons had no effect, and bulkier phosphine 'poisons' such as $\mathrm{PPh}_{3}$ and $\mathrm{PCy}_{3}$ actually increased the rate of catalysis, indicating very small and selective active sites. We hypothesized that the increased rate was a result of stabilization from the bulky groups which helped prevent or minimize agglomeration of the Fe NPs. We were also able to completely poison our active sites with $15 \%$ pentanethiol which we were able to detect using electron microscopy and EDX as discussed below. We also applied this methodology to our 5,5,5-systems, attempting to poison catalysis with only $10 \% \mathrm{PMe}_{3}$ relative to iron, but only observed proportionate catalytic rate decreases. ${ }^{19}$ It was only in the presence of one equivalent of $\mathrm{PMe}_{3}$ relative to precatalyst that activity was severely diminished, once again supporting not only that the two systems operate via different mechanisms, but that one system was likely NPs whereas the other appeared to be operating 
via a homogeneous pathway. The 6,5,6-system was also shown to be catalytically active for the reverse reaction, oxidative kinetic resolution, and we were able to similarly inhibit catalysis using only $10 \% \mathrm{PMe}_{3}{ }^{55}$

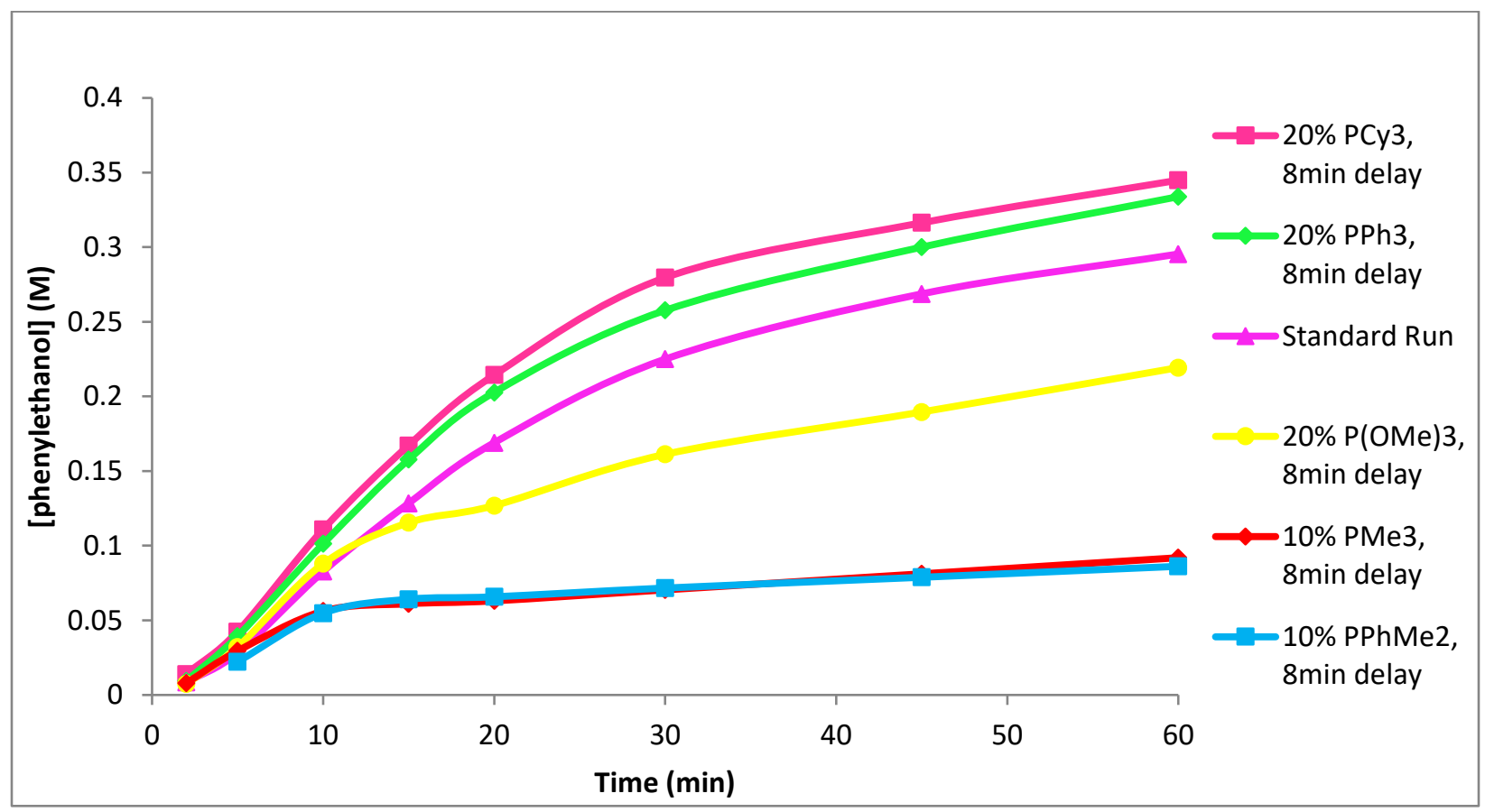

Figure 4: Catalytic profiles of TH of acetophenone to 1-phenylethanol using iron NPs depicting the influence of various poisoning agents on catalytic activity (poisons added at 8 minutes to allow for active species to form). Reprinted with permission from Reference 44. Copyright 2012 American Chemical Society.

Manners and coworkers have recently published the use of two structurally similar iron catalysts for the dehydrogenation of amine-boranes, $\left[\mathrm{CpFe}(\mathrm{CO})_{2}\right]_{2}(\mathbf{A})$ and $\mathrm{CpFe}(\mathrm{CO})_{2} \mathrm{I}(\mathbf{B})\left(\mathrm{Cp}=\eta-\mathrm{C}_{5} \mathrm{H}_{5}\right)$, both of which require photo-irradiation to activate. ${ }^{54}$ During studies to further understand the mechanism, they observed different reactive intermediates in the case of (A) versus (B). Following activation of either (A) or (B), they allowed catalysis to reach $50 \%$ conversion before splitting the reaction into two batches. One batch was allowed to react normally, and $10 \% \mathrm{PMe}_{3}$ was added to the other batch. The batches that were not treated with $\mathrm{PMe}_{3}$ proceeded normally, whereas the batches with $\mathrm{PMe}_{3}$ were affected: (A) was completely stopped, and (B) was slowed. Addition of 1 equivalent of $\mathrm{PMe}_{3}$ instead of $10 \%$ (relative to $\mathrm{Fe}$ ) completely stopped catalysis. This series of tests provided strong evidence, much like our tests, that (A) formed a heterogeneous NP catalyst when activated, whereas (B) was homogeneous in nature. This was further probed using a wide variety of techniques including TEM, EDX, DLS (discussed below) and computational (DFT) studies, to provide a strong collection of evidence supporting the true nature of the catalyst in both cases. 
The other type of NP poisoning test is mercury poisoning. It is a well-established tool, commonly used for bulk heterogeneous and some NP catalytic systems typically based on platinum group metals, which form amalgams with $\mathrm{Hg}$. To successfully use this test, one should add an excess of mercury after the commencement of catalysis to ensure that it is reacting with the activated catalyst, not the catalyst precursor, by forming an amalgam with the exposed surface and inhibiting catalysis., 1,47,56-61 This methodology has been widely used for nearly 100 years $^{59}$ and its applications have been thoroughly reviewed previously. ${ }^{1,2}$ It is important, however, to draw attention to the potential false-positive and falsenegative results that are possible with this method. First is that mercury can poison homogeneous catalysts, and this has been shown by Dyson. ${ }^{62}$ In his article he discusses the difficulties associated with distinguishing homogeneous from heterogeneous catalysis as it pertains to arene hydrogenation, and suggests that mercury may react with metals and ligands, deactivating homogeneous systems. This would provide a 'false-positive' result for heterogeneous catalysis. Mercury reacting with metal precursors deactivating homogeneous pathways has also been shown with $\mathrm{Pt}(0)$ species. ${ }^{63,64}$ Secondly, mercury is not able to form a stable amalgam with all metals ${ }^{65}$ and therefore successful catalysis (not poisoned) cannot act as proof of homogeneity. There have been many recent examples of this issue, particularly with iron, where the active catalyst was tolerant to an excess of mercury and was shown to be NPs. ${ }^{44,66,67}$

\section{Electron Microscopy and Energy Dispersive X-Ray}

Following our in operando studies on our iron systems which suggested that the 6,5,6-system operated via a NP mechanism versus our 5,5,5-system which appeared to be homogeneous, we were interested in imaging the catalytic solutions using electron microscopy. Electron microscopy is a well-studied, advanced technique, ${ }^{68}$ that is one of the most common methods of probing and analysing nanoparticle samples. Transmission (TEM), Scanning (SEM) and Scanning Transmission (STEM) electron microscopes can be used to visually detect the presence (or lack) of nanoparticles, as well as examine their size, shape and distributions thereof, however a more detailed analysis of the full breadth of these techniques is beyond the scope of this review. ${ }^{69}$ With limited exceptions, ${ }^{70} \mathrm{EM}$ is typically done on dried samples, making direct analysis of catalytic reactions challenging. Therefore, this technique is best described as an ex situ method of analysis, as opposed to the in operando techniques previously discussed. For our purposes, we applied STEM to analyse our catalytic solutions and control experiments. For the 6,5,6-system, we were able to characterize small, 3-4 $\mathrm{nm}$ iron particles that were partially agglomerated. We were unable to determine whether the samples were agglomerated during catalysis, or if that was an effect of drying, however DLS studies discussed below suggest that agglomeration occurred in the solution state. For the 5,5,5-system 
we analysed a sample of the activated bis-ene-amido species discussed previously but were unable to detect NPs. ${ }^{36}$ The lack of nanoparticles cannot be used to prove homogeneous catalysis as these instruments do have lower levels of detection and the characterization of particles below $1 \mathrm{~nm}$ in diameter is not often possible, however these results do suggest that the two iron systems operate differently. ${ }^{2,71}$ Another important issue to address is that the presence of nanoparticles does not prove they are the active catalytic species because 1) nanoparticles may form as an inactive side reaction or an active homogeneous catalyst may gradually deactivate into nanoparticles ${ }^{63}$ or 2 ) the electron beam may induce nanoparticle formation from a homogeneous sample, as this has been reported on multiple occasions. ${ }^{47,72-}$ 75 One must also be aware that reports do exist of the electron beam inducing phase changes on a heterogeneous surface, which can influence the resultant structure observed by EM. ${ }^{76}$ Given these potential problems, it becomes critical to consider every catalytic system individually and devise and test all potential control experiments: ensure that the size and concentration of catalyst will allow for NP formation and visualisation, that beam damage or beam-induced NP formation is not occurring using similar complexes that are known to be homogeneous, and much more. For a more detailed review on the importance of controls and fully understanding the catalyst system, see Stracke and Finke $\mathrm{A}^{4}$ and Bayram et. al..$^{75}$

There are many examples of nanoparticle catalysts being analysed using electron microscopy for both base metal ${ }^{54,77-81}$ and precious metal ${ }^{16,43,82-86}$ systems. Select examples include the detection of small ( 2 $\mathrm{nm}$ ) monodisperse iron nanoparticles for $\mathrm{C}-\mathrm{C}$ bond hydrogenation by Chaudret, ${ }^{77}$ the breakthrough iridium nanocluster analysis work by Lin and Finke showing the time sensitive nature of Ir $_{300}$ nanoclusters as the monodisperse particles agglomerate over time, ${ }^{83}$ and the detection of $0.5-2 \mathrm{~nm}$ platinum nanoparticles coated onto $\mathrm{TiO}_{2}$ single crystal thin films for $\mathrm{CO}_{2}$ photoreduction by Biswas and coworkers. ${ }^{87}$

In addition to standard imaging capabilities, many electron microscopes are also capable of running Energy-Dispersive X-ray Spectroscopy (EDX) which allows for elemental analysis in selective windows, in conjunction with imaging. ${ }^{88}$ Our group took this methodology one step further by using EDX to analyse samples from activated catalytic solutions (6,5,6-system) and poisoned catalyst solutions. ${ }^{44}$ The addition of $15 \%$ pentanethiol to our activated solutions completely stopped catalysis, as discussed previously, indicating that the thiol was bound to the active species in the poisoned solutions. Using EDX analysis we were able to compare the relative amounts of Fe to $\mathrm{S}$ on both the poisoned and un-poisoned NPs for a large number of particles in each experiment (ensuring statistical accuracy). Results indicated that there was in fact an increase in the S:Fe ratio in the poisoned samples, which corresponded to an approximate 
0.13:1.0 molar ratio of S:Fe following the addition of the poison. This provided very strong evidence that the poison was only bound to the iron NPs, and that the NPs were likely the active species during catalysis. This unique method of using a combination of ex situ and in operando techniques as a single test, rather than individually has also opened new avenues of investigation in terms of potential tests for heterogeneity. We also used EDX to analyse our 5,5,5-system during STEM analysis and were able to show that detectable levels of iron were present throughout the sample, as would be expected for a homogeneous system, albeit not proving homogeneity.

\section{Dynamic Light Scattering}

Following our size-characterization of our Fe NPs using STEM, we were interested in further size distribution characterization using dynamic light scattering (DLS). Dynamic Light Scattering (DLS) is a very powerful technique for determining the various sizes of metal species in solution, allowing for facile in operando studies of catalytic solutions..$^{89}$ In his review, Crabtree explains that unlike electron microscopy, which is limited to dry, ex-situ analysis, DLS gives a much more realistic picture of the species present during catalysis. ${ }^{2} \mathrm{He}$ also emphasizes the versatility of DLS in that it can often detect particles smaller than the detection limit of traditional microscopy, yielding the same sizing information. Historically this technique has seen much more widespread use to either confirm or disprove the presence of NPs, 7,63,64,90 but has not been exploited by catalytic chemists in recent years, with few exceptions. ${ }^{54}$ It is once again important to point out that although this technique can demonstrate the presence of NPs, it cannot act as stand-alone support of a heterogeneous mechanism; further in operando studies are needed in conjunction with DLS. Data analysis is also not always straightforward; for real life samples there is often a distribution of particle sizes and the experimentally determined particle radius is actually a weighted average, called the 'z-average size' ${ }^{89}$ Therefore it is critical to ensure that disproportionately large agglomerates or organics such as polymers and dust are not included in analysis as they can drastically skew the average. Another important note with this technique is that the signal scales with the size of the particles. ${ }^{91}$ This indicates that very small particles may be below the detection limits of the instrument (typically on the order of $<2 \mathrm{~nm}$ ), indicating that although an experiment may suggest that there are no NPs present, it is possible that the catalyst is in fact very small heterogeneous particles or clusters, and therefore control experiments are needed to confirm that the desired species are in fact detectable. We encountered similar problems while attempting to analyse our small 3-4 nm Fe NPs with DLS. Due to the highly reactive nature of the NP surface as observed with by XPS (below) and STEM, agglomeration into 
larger species occurred, yielding broad signals for large agglomerates, and minimizing the chances of detecting small monodisperse species.

\section{X-Ray Photoelectron Spectroscopy}

During STEM and EDX analysis of our activated 6,5,6-system we observed the presence of oxides on our Fe NPs, and we were therefore interested in investigating whether the entire particle was oxidized, or whether the particle was still zero-valent iron with surface oxidation. For this we turned to X-ray photoelectron spectroscopy (XPS), which is a useful technique for determining the valency of metals and the binding state of organic ligands by comparing spectra to literature values. ${ }^{92}$ Samples are typically dried and analysed as a powder or film, and the window, or area examined, is large, and XPS is therefore useful for indicating the valencies of all metal species present during catalysis (both homogeneous and heterogeneous) as well as organic ligands present. For our 6,5,6-system we were able to show that the primary species observed was in fact zero-valent iron, with some $\mathrm{Fe}_{2} \mathrm{O}_{3}$ present due to surface oxidation during analysis. ${ }^{44}$ XPS analyses can be selectively run on individual elements, which we were able to take advantage of by probing phosphorus excitation peaks. Our organic stabilizer (a P-N-N-P tetradentate ligand) partially dissociated and oxidized during catalysis according to NMR data ${ }^{33}$ which we confirmed by identifying a tri- and pentavalent peak in the P $2 p$ XPS spectra. ${ }^{44}$ Also taking advantage of this capability was Manners and coworkers. ${ }^{57}$ who were able to detect the binding of phosphine poisoning agents onto a Rh(0) NP surface by analysing the phosphorus spectra. During the dehydrocoupling of amine-boranes they found that their catalysts were deactivating, and confirmed that small phosphine poisoning agents, such as $\mathrm{PMe}_{3}$, could poison catalysis. They confirmed that this was going through phosphine ligation on the NP surface using XPS analysis, once again demonstrating the power of combining multiple tools poisoning and XPS.

XPS was also used by Cho et. al. to analyse their Au NP catalysts which were active for cyanosilylation of aldehydes. ${ }^{61}$ They found that during catalysis there were both homogeneous (leached gold) and heterogeneous (Au NP) species present in a $\sim$ 4:1 ratio, respectively, that were active for catalysis. Grosvenor et. al. used this technique for the study ferrous $\left(\mathrm{Fe}^{2+}\right)$ and ferric $\left(\mathrm{Fe}^{3+}\right)$ compounds, which allowed for a detailed analysis of the spectra of the multiple oxidation states of iron in $\mathrm{Fe}_{3} \mathrm{O}_{4} .^{93}$ It is important to once again stress that this technique cannot act as stand-alone evidence for NP catalysis; an important example of this was reported by Bayram et. al. who showed through XPS that the major metal species for benzene hydrogenation was a Rh (0) species. The active catalyst, however, was shown, using 
a wide variety of techniques, to likely be $\mathrm{Rh}_{4}$ cluster compounds. ${ }^{75}$ This again emphasizes the importance of employing a large number of techniques, as well as running the key control experiments.

\section{Magnetometry}

With strong evidence in hand that our 6,5,6-system was generating active Fe NPs in catalysis, we were interested in studying the unique magnetic behaviour of the iron species using magnetometry. Specifically, we were interested in further characterizing the detected NPs, and determining whether there were detectable iron impurities in the sample. Superconducting Quantum Interference Device (SQUID) Magnetometry is a technique capable of analysing catalytic solutions of first row transition metals, in situ. The use of this technique to identify NPs relies heavily on the diverse range of magnetic properties of metals in different states, particularly diamagnetic, paramagnetic and superparamagnetic species. ${ }^{94,95}$ The two standard SQUID experiments typically run are zero field cool-field cool (ZFC-FC) and hysteresis runs. ${ }^{67}$ The first is a ZFC-FC experiment, where samples are first supercooled to $\sim 2 \mathrm{~K}$ in zero field, then warmed gradually under the influence of a set magnetic field to $\sim 100 \mathrm{~K}$, and then cooled back to $2 \mathrm{~K}$ under the same field yielding a plot like the one in obtained by de Vries et. al. in Figure 5 (bottom). For a diamagnetic sample, one would expect a slightly negative and flat (constant) plot, whereas for a paramagnetic sample, one would expect a complete overlay of the FC plot. Figure 5 (bottom) instead demonstrates a broad peak around 10-12 $\mathrm{K}$. This is the blocking temperature (BT) and indicates the point at which the nanoparticles break out of their blocked regime and begin to become superparamagnetic, indicative of metal nanoparticles. ${ }^{44,67,96}$ The second experiments typically run are hysteresis loops, such as those in Figure 5 (top). At set temperatures, the instrument scans forward and backward through a range of magnetic fields. At temperatures above the BT, such as $40 \mathrm{~K}$ in Figure 5, the plots exactly overlap each other, but at temperatures below the BT ( $3 \mathrm{~K})$ hysteresis is observed, and the width of separation of the traces is referred to as the coercive field. 

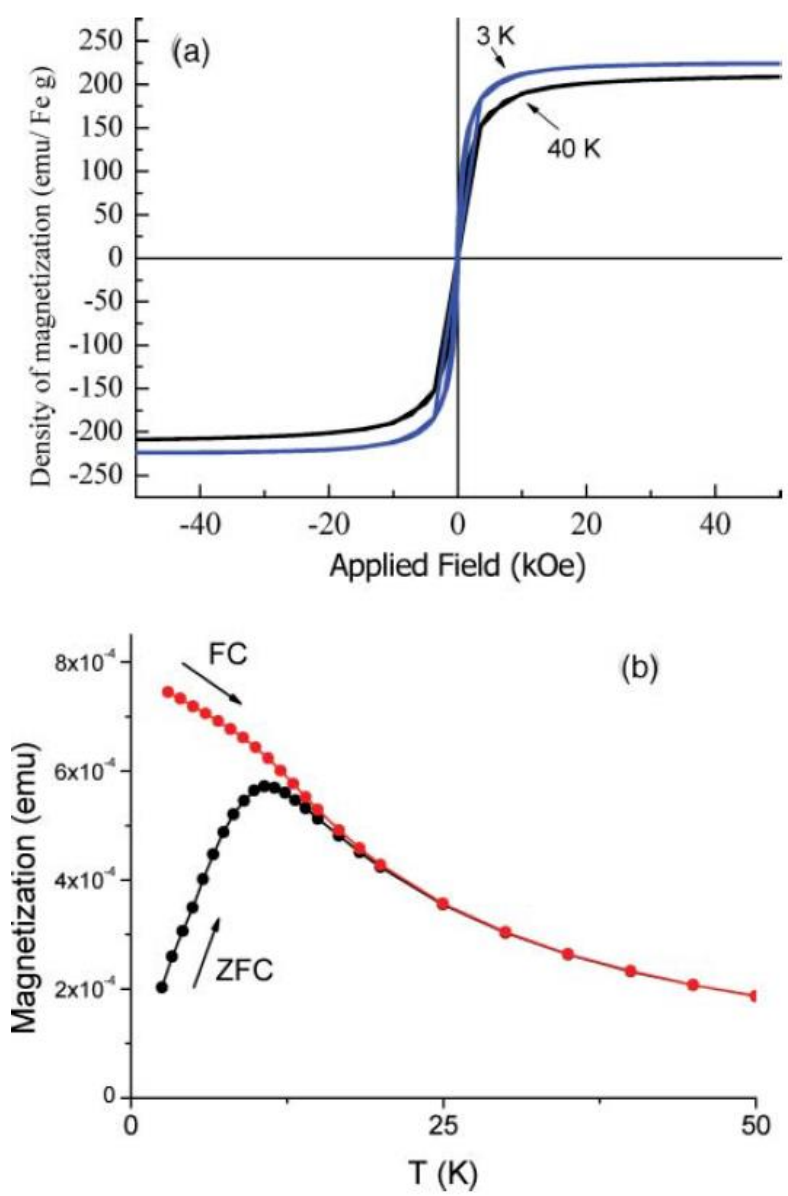

Figure 5: Standard plots obtained using SQUID Magnetometry analysis. Top - hysteresis loops through varying magnetic fields at two set temperatures ( $3 \mathrm{~K}$ and $40 \mathrm{~K}$ ). Bottom - ZFC-FC experiment depicting a blocking temperature. Reproduced from Reference 67 with permission from The Royal Society of Chemistry.

These experiments are not as common in the catalytic literature as they require fairly specialized equipment, but have begun to see widespread use in the characterization of iron NPs in the 2-3 nm range ${ }^{97,98}$ the $3-4 \mathrm{~nm}$ range ${ }^{44,67}$ and the $7 \mathrm{~nm}$ range. ${ }^{96}$ For our 6,5,6-system we ran both the ZFC-FC and hysteresis experiments and generated similar plots to those depicted in Figure 5 . The blocking temperature of our system was $7 \mathrm{~K}$ (Figure 6), which was comparable to the $10 \mathrm{~K}$ for the $3 \mathrm{~nm}$ Fe NPs reported by de Vries et.al. ${ }^{67}$ consistent with the general size and morphology determined from STEM and XPS.$^{44}$ The curve depicted in Figure 6 is also fairly smooth in shape, indicating the presence of minimal paramagnetic impurities. 


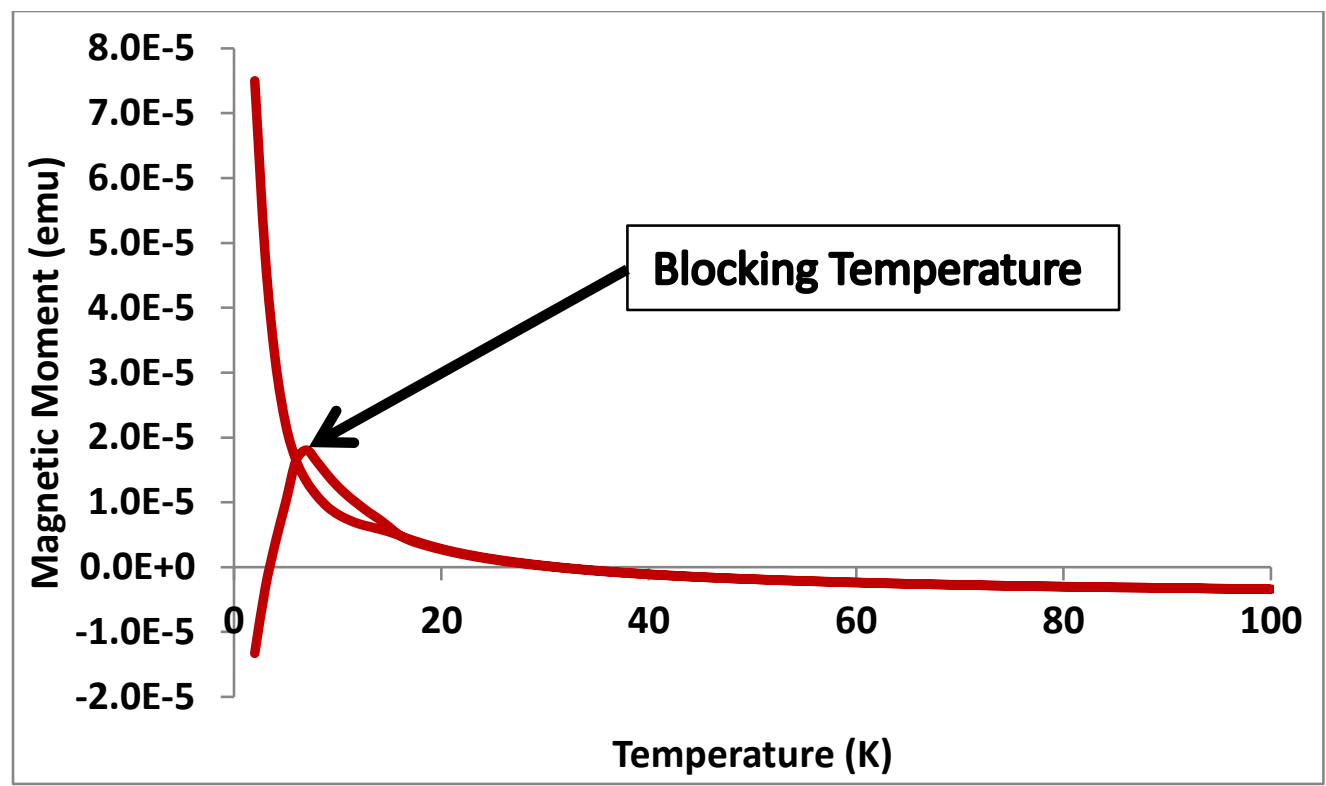

Figure 6: Temperature dependence of the Zero Field Cooling-Field Cooling (ZFC-FC) SQUID experiment with our 6,5,6-system, indicating a blocking temperature of $7 \mathrm{~K}$. Reprinted with permission from Reference 44 . Copyright 2012 American Chemical Society.

\section{Substrate-Containing Polymer Experiments}

Given the strong evidence that the formation of Fe NPs was occurring with our 6,5,6-system, we were interested in investigating multiphasic tests to probe whether the NPs were the active species during catalysis. The use of multiphasic systems to test heterogeneity is a highly useful and underutilized tool. The general concept of this type of test is that a substrate is bound within the pores of porous polymer, such as a commercially available resin, and catalysis is run using the resin as the substrate. Homogeneous catalysts are small enough to permeate the pores and do catalysis, yielding product, whereas heterogeneous catalysts are too large and the polymer remains unchanged. ${ }^{2}$ This was conventionally used to determine if homogeneous catalysts were leaching from heterogeneous catalysts, such as the work done by Davies et. al. who showed that palladium was leaching from Pd/C yielding active homogeneous species. ${ }^{99}$ In his review, Crabtree also emphasizes the importance of this test as it can indicate whether metal species have leached into solution, which can cause product contamination, an important issue in the pharmaceutical industry. ${ }^{2}$

For our 6,5,6-system, we modified a commercially available Wang resin (benzyl alcohol functionality) to include a benzaldehyde functionality inside the pores using pyridinium chlorochromate (PCC). The aldehyde was successfully hydrogenated using $\mathrm{NaBH}_{4}$ and $\mathrm{AlMe}_{3}$ (Meerwein-Pondorf-Verley type 
catalyst ${ }^{100}$ but showed no conversion to the hydrogenated alcohol in the presence of our activated iron catalysts, lending strong evidence that the active species are heterogeneous. ${ }^{44}$ Similarly, we used PCC followed by $\mathrm{MeMgCl}$ to incorporate a 1-phenylethanol functionality within the polymer pore to test our oxidation catalyst system. ${ }^{55}$ Monometallic PCC was able to completely oxidize to the acetophenone functionality, whereas our iron catalyst showed no conversion, suggesting that the active species, once again, were NPs. Analysis was done using semi-solid state MAS ${ }^{13} \mathrm{C}$ NMR on pre-swollen polymer beads ${ }^{101}$ to indicate the presence of $\mathrm{C}=\mathrm{O}$ versus $\mathrm{C}-\mathrm{OH}$ bonding states. ${ }^{102}$ Other useful analysis methods for the functionalized beads include the use of IR spectroscopy, ${ }^{44}$ or selectively untethering the functional group from the polymer following catalysis and running standard analysis techniques (NMR, GC, etc.). ${ }^{103}$

Collman et. al. reported the use of a $\mathrm{C}=\mathrm{C}$ cross-linked Merrifield resin to distinguish homogeneous from heterogeneous hydrogenation using the resin directly as the substrate. ${ }^{104}$ These resins were used for a series of precious metal catalysts and proved highly effective at distinguishing homogeneous from heterogeneous systems. Although there are several limitations to this methodology, specifically the types of substrates that can be assembled within the pores of the polymer, it has proven to be a powerful tool for a variety of applications. A few points to keep in mind with the application of this technique: 1) the catalyst being tested must be active towards the substrate incorporated into the polymer; 2 ) the polymer cannot act as a poison to catalysis; 3 ) the catalyst must be active on the timescale of polymer catalysis (permeating the pore and catalysing a reaction inside a polymer will take longer than for free substrate and the catalyst must remain active for the test to be accurate); and 4) an accurate method of polymer analysis must be designed/devised. For our studies, this technique was best viewed as a more qualitative mechanistic probe, as opposed to a quantitative, kinetic probe, however it still yielded highly valuable information.

\section{Chirality}

The observation of asymmetric induction is no longer valid support for homogeneity as well-defined and enantioselective NP catalysts are becoming more widely reported. Well-defined NP catalysts coated with chiral ligands have been shown to perform asymmetric catalysis to yield chiral products. ${ }^{11}$ For our $6,5,6$ system we reported the use of chiral tetradentate P-N-N-P ligands on iron NPs for the asymmetric TH of ketones to chiral alcohols with modest enantioselectivities of $65 \%$ for acetophenone conversion. ${ }^{44}$ However, using the achiral variant of the P-N-N-P ligand we saw no enantioselectivity, indicating that the ligand was responsible for inducing chirality, as opposed to an inherently chiral metal surface. ${ }^{105}$ We then took these systems a step further and tested our chiral Fe NP system for the reverse reaction, oxidative kinetic resolution of racemic alcohols to generate enantioenriched alcohols. Although rates were moderate, we successfully showed the first application of chiral NPs for this type of catalysis. ${ }^{55}$ The use of 
chiral ligands to induce asymmetric transformations on NP surfaces has been employed recently by Gao for iron NPs coated with macrocyclic P-N-N-P-N-N- ligands for direct asymmetric hydrogenation (Li, Y.; Yu, S.; Wu, X.; Xiao, J.; Shen, W.; Dong, Z.; Gao, J. J. Am. Chem. Soc. 2014, 136, 4031) and by Chaudret for asymmetric TH using ruthenium NPs coated in chiral N-donor ligands. ${ }^{106}$ Burgi et. al. have also shown that a chiral gold cluster can be formed using achiral thiolate ligands (intrinsically chiral cluster), and the $\mathrm{Au}_{38}(\mathrm{SR})_{24}$ cluster is capable of racemizing in solution under moderate conditions. ${ }^{107-109}$

Initial discoveries in this field came from Osawa ${ }^{110}$ who used tartaric acid on Raney nickel for ketone hydrogenation and from Orito who used platinum on carbon with cinchonidine (CD) for hydrogenation. ${ }^{111,112}$ The Orito reaction has since been built upon by Bönnemann ${ }^{113}$ who used palladium and platinum colloids treated with cinchonidine to hydrogenate ketones, and more recently by Baiker ${ }^{114-}$ ${ }^{116}$ who bound cinchonidine coated platinum colloids to magnetite particles to allow for facile separation and reuse. The Orito Reaction has been studied and improved upon significantly over the past couple decades, and those interested in more information are encouraged to read recent reviews. ${ }^{117-119}$

To round out our discussion of chirality and NPs for asymmetric induction, we would like to address a recent article by McBreen et. al. who described the use of a scanning tunneling microscope (STM) to visually analyse the orientation of chiral modifiers and prochiral substrates on a platinum [111] surface. ${ }^{120}$ Using STM they could map out the most common orientations of ligand relative to substrate and run catalysis to determine the product enantiopurity. Then, using DFT calculations, they could separately predict the lowest energy conformations (orientations of ligand relative to substrate) and resulting product e.e., which was consistent with experimental data. This not only supports the applicability of NPs to asymmetric catalysis, but demonstrates that much like homogeneous systems chirality on a surface can be predictable.

\section{Other Methodologies}

The techniques discussed thus far have been successfully applied to several of our catalytic reactions employing the 6,5,6-precatalyst; the TH of ketones, ${ }^{33,44}$ the oxidative kinetic resolution of alcohols ${ }^{55}$ and the dehydrogenation of ammonia-borane (AB). ${ }^{81}$ There are several other well reported and highly versatile techniques that can also be applied to the title question; however they have been rigorously reviewed previously and will not be discussed in detail here. ${ }^{1,2,4,75}$ Some of these techniques include X-ray diffraction (powder or single-crystal) and Mössbauer spectroscopy, both of which can be applied to determining the valency and structure of a metal centre (only select metals feasible with Mössbauer) in either homogeneous or heterogeneous systems. ${ }^{13,83,121-123}$ Extended X-ray absorption fine structure 
(EXAFS) and small angle X-ray scattering (SAXS) are growing in popularity as useful in operando techniques for identifying and characterizing metal species in the solution state. ${ }^{75,124,125}$ Other useful techniques include UV-Vis spectroscopy, electrochemistry, IR, Raman, mass spectrometry, and many more, and these techniques were recently reviewed by Stracke et. al. ${ }^{4}$

\section{Conclusions}

This comparison of the first and second generation catalysts developed in our lab is an important example of why it is so critical to study the reaction mechanism of every catalyst system, regardless of how similar they may seem. In this review we highlighted two generations of iron TH catalysts developed in our group, the 6,5,6 and 5,5,5-systems and detail the various steps that were taken to ultimately show that they operate via very different mechanistic routes. We have provided strong evidence that our 6,5,6-system generates active Fe NPs in solution, ${ }^{33,44}$ whereas our 5,5,5-system remains homogeneous upon activation. ${ }^{19,20,34}$ This was initially probed using NMR and computational (DFT) methods, which indicated that the 6,5,6-system was likely forming Fe (0) species in solution due to ligand folding, whereas the 5,5,5ligand system was too rigid to form such a species. Both catalytic reaction profiles exhibited an induction period and sigmoidal reaction curve; for the 6,5,6-system this was attributed to the generation of Fe (0), whereas for the 5,5,5-system this was due to the energetically demanding formation of active intermediates with partially reduced ligand backbones. Small phosphine and thiol poisons were then demonstrated to completely stop catalysis in the 6,5,6-system with only $10 \%$ loading (relative to Fe), whereas the 5,5,5-system required a full equivalent. STEM, EDX, XPS and SQUID were used to determine that the 6,5,6-system was generating small, 3-4 nm Fe NPs during catalysis, and polymer-bound substrate experiments suggested that the active species was too large to permeate the pores of a polymer. Compiling this information, although the two systems appear to be structurally similar, we suggest that the 6,5,6-system is heterogeneous, whereas the 5,5,5-system is homogeneous in nature. This review highlights the importance of applying a wide range of techniques to piece together evidence to deduce a systems' true mechanism as it applies to our own work, but also how powerful and widely applicable this methodology can be to any range of catalytic transformations. 


\section{Acknowledgements}

We would like to thank the Natural Sciences and Engineering Research Council (NSERC) for a Discovery grant to R.H.M. and for a Canadian Graduate Scholarship and a Vanier Scholarship for J.F.S..

\section{References}

(1) Widegren, J. A.; Finke, R. G. J. Mol. Catal. A: Chem. 2003, 198, 317-341.

(2) Crabtree, R. H. Chem. Rev. 2012, 112, 1536-1254.

(3) Lin, Y.; Finke, R. G. Inorg. Chem. 1994, 33, 4891-4910.

(4) Stracke, J. J.; Finke, R. G. ACS Catal. 2014, 4, 909-933.

(5) Artero, V.; Fontecave, M. Chem. Soc. Rev. 2013, 42, 2338-2356.

(6) Yan, N.; Yuan, Y.; Dyson, P. J. Dalton Trans. 2013, 42, 13294-13304.

(7) Lewis, L. N. Chem. Rev. 1993, 93, 2693-2730.

(8) Astruc, D.; Lu, F.; Aranzaes, J. R. Angew. Chem. Int. Ed. 2005, 44, 7852-7872.

(9) Roucoux, A.; Schulz, J.; Patin, H. Chem. Rev. 2002, 102, 3757-3778.

(10) Phan, N. T. S.; Van Der Sluys, M.; Jones, C. W. Adv. Synth. Catal. 2006, 348, 609-679.

(11) Ranganath, K. V. S.; Glorius, F. Catal. Sci. Technol. 2011, 1, 13-22.

(12) Platt, J. R. Science 1964, 146, 347-353.

(13) Inorganic Nanoparticles; Altavilla, C.; Ciliberto, E., Eds.; Taylor \& Francis Group: Boca Raton, FL, 2011.

(14) Lucas, J. M.; Tuan, C.-C.; Lounis, S. D.; Britt, D. K.; Qiao, R.; Yang, W.; Lanzara, A.; Alivisatos, A. P. Chem. Mater. 2013, 25, 1615-1620.

(15) Rafter, E.; Gutmann, T.; Low, F.; Buntkowsky, G.; Philippot, K.; Chaudret, B.; van Leeuwen, P. W. N. M. Catal. Sci. Technol. 2013, 3, 595-599.

(16) Zahmakran, M.; Philippot, K.; Ozkar, S.; Chaudret, B. Dalton Trans. 2012, 41, 590-598.

(17) Roucoux, A.; Philippot, K. In The Handbook of Homogeneous Hydrogenation; Vries, J. G. d., Elsevier, C. J., Eds.; Wiley-VCH: 2007, p 217-256.

(18) Mikhailine, A.; Lough, A. J.; Morris, R. H. J. Am. Chem. Soc. 2009, 131, 1394-1395.

(19) Mikhailine, A. A.; Maishan, M. I.; Lough, A. J.; Morris, R. H. J. Am. Chem. Soc. 2012, 134, 12266-12280.

(20) Zuo, W.; Lough, A. J.; Li, Y. F.; Morris, R. H. Science 2013, 342, 1080-1083.

(21) Jeffery, J. C.; Rauchfuss, T. B.; Tucker, P. A. Inorg. Chem. 1980, 19, 3306

(22) Gao, J.-X.; Ikariya, T.; Noyori, R. Organometallics 1996, 15, 1087-1089.

(23) Gao, J.-X.; Wan, H.-L.; Wong, W.-K.; Tse, M.-C.; Wong, W.-T. Polyhedron 1996, 15, 1241-1251.

(24) Gao, J. X.; Zhang, H.; Yi, X. D.; Xu, P. P.; Tang, C. L.; Wan, H. L.; Tsai, K. R.; Ikariya, T. Chirality 2000, 12, 383-388.

(25) Jothimony, K.; Vancheesan, S.; Kuriacose, J. C. J. Mol. Catal. 1985, 32, 11-16.

(26) Jothimony, K.; Vancheesan, S. J. Mol. Catal. 1989, 52, 301-304.

(27) Chen, J. S.; Chen, L. L.; Xing, Y.; Chen, G.; Shen, W. Y.; Dong, Z. R.; Li, Y. Y.; Gao, J. X. Acta Chim. Sin. (Huaxue Xuebao) 2004, 62, 1745-1750.

(28) Sui-Seng, C.; Freutel, F.; Lough, A. J.; Morris, R. H. Angew. Chem. Int. Ed. 2008, 47, 940-943.

(29) Sui-Seng, C.; Haque, F. N.; Hadzovic, A.; Pütz, A. M.; Reuss, V.; Meyer, N.; Lough, A. J.; Zimmer-De luliis, M.; Morris, R. H. Inorg. Chem. 2009, 48, 735-743.

(30) Meyer, N.; Lough, A. J.; Morris, R. H. Chem. Eur. J. 2009, 15, 5605-5610.

(31) Lagaditis, P. O.; Lough, A. J.; Morris, R. H. Inorg. Chem. 2010, 49, 10057-10066.

(32) Sues, P. E.; Lough, A. J.; Morris, R. H. Organometallics 2011, 30, 4418-4431. 
(33) Prokopchuk, D. E.; Sonnenberg, J. F.; Meyer, N.; Zimmer-De luliis, M.; Lough, A. J.; Morris, R. H. Organometallics 2012, 31, 3056-3064.

(34) Prokopchuk, D. E.; Morris, R. H. Organometallics 2012, 31, 7375-7385.

(35) Lagaditis, P. O.; Sues, P. E.; Sonnenberg, J. F.; Wan, K. Y.; Lough, A. J.; Morris, R. H. J. Am. Chem. Soc. 2014, 136, 1367-1380.

(36) Lagaditis, P. O.; Lough, A. J.; Morris, R. H. J. Am. Chem. Soc 2011, 133, 9662-9665.

(37) Kohl, S. W.; Weiner, L.; Schwartsburd, L.; Konstantinovski, L.; Shimon, L. J. W.; Ben-David, Y.; Iron, M. A.; Milstein, D. Science 2009, 324, 74-77.

(38) Gunanathan, C.; Milstein, D. Acc. Chem. Res. 2011, 44, 588-602.

(39) Dunlop-Brière, A. F.; Baird, M. C.; Budzelaar, P. H. M. J. Am. Chem. Soc. 2013, 135, 17514-17527.

(40) Sauriol, F.; Sonnenberg, J. F.; Chadder, S. J.; Dunlop-Brière, A. F.; Baird, M. C.; Budzelaar, P. H. M. J. Am. Chem. Soc 2010, 132, 13357-13370.

(41) Clapham, S. E.; Hadzovic, A.; Morris, R. H. Coord. Chem. Rev. 2004, 248, 2201-2237.

(42) Novio, F.; Philippot, K.; Chaudret, B. Catal. Lett. 2010, 140, 1-7.

(43) Lara, P.; Rivada-Wheelaghan, O.; Conejero, S.; Poteau, R.; Philippot, K.; Chaudret, B. Angew. Chem. Int. Ed. 2011, 50, 12080-12084.

(44) Sonnenberg, J. F.; Coombs, N.; Dube, P. A.; Morris, R. H. J. Am. Chem. Soc. 2012, 134, 5893-5899.

(45) Besson, C.; Finney, E. E.; Finke, R. G. J. Am. Chem. Soc. 2005, 127, 8179-8184.

(46) Besson, C.; Finney, E. E.; Finke, R. G. Chem. Mat. 2005, 17, 4925-4938.

(47) Hagen, C. M.; Widegren, J. A.; Maitlis, P. M.; Finke, R. G. J. Am. Chem. Soc. 2005, 127, 4423-4432.

(48) Watzky, M. A.; Finke, R. G. J. Am. Chem. Soc. 1997, 119, 10382-10400.

(49) Watzky, M. A.; Finney, E. E.; Finke, R. G. J. Am. Chem. Soc. 2008, 130, 11959-11969.

(50) Mondloch, J. E.; Yan, X.; Finke, R. G. J. Am. Chem. Soc. 2009, 131, 6389-6396.

(51) Suzdalev, I. P.; Suzdalev, P. I. Russ. Chem. Rev. 2001, 70, 177-210.

(52) Hornstein, B. J.; Aiken, J. D.; Finke, R. G. Inorg. Chem. 2002, 41, 1625-1638.

(53) Bayram, E.; Finke, R. G. ACS Catal. 2012, 1967-1975.

(54) Vance, J. R.; Schäfer, A.; Robertson, A. P. M.; Lee, K.; Turner, J.; Whittell, G. R.; Manners, I. J. Am. Chem. Soc. 2014, 136, 3048-3064.

(55) Sonnenberg, J. F.; Pichugin, D.; Coombs, N.; Morris, R. H. Top. Catal. 2013, 56, 1199-1207.

(56) Jaska, C. A.; Temple, K.; Lough, A. J.; Manners, I. J. Am. Chem. Soc. 2003, 125, 9424-9434.

(57) Clark, T. J.; Jaska, C. A.; Turak, A.; Lough, A. J.; Lu, Z. H.; Manners, I. Inorg. Chem. 2007, 46, 7394-7402.

(58) Whitesides, G. M.; Hackett, M.; Brainard, R. L.; Lavalleye, J. P. P. M.; Sowinski, A. F.; Izumi, A. N.; Moore, S. S.; Brown, D. W.; Staudt, E. M. Organometallics 1985, 4, 1819-1830.

(59) Paal, C.; Hartmann, W. Chem. Ber. 1918, 51, 711-737.

(60) Weddle, K. S.; Aiken, J. D.; Finke, R. G. J. Am. Chem. Soc. 1998, 120, 5653-5666.

(61) Cho, W. K.; Lee, J. K.; Kang, S. M.; Chi, Y. S.; Lee, H. S.; Choi, I. S. Chem. Eur. J. 2007, 13, 6351-6358.

(62) Dyson, P. J. Dalton Transactions 2003, 2964-2974.

(63) Stein, J.; Lewis, L. N.; Gao, Y.; Scott, R. A. J. Am. Chem. Soc. 1999, 121, 3693-3703.

(64) Lewis, L. N.; Lewis, N. J. Am. Chem. Soc. 1986, 108, 7228-7231.

(65) Lihl, F. Z. Metallk 1953, 44, 160.

(66) Bedford, R. B.; Betham, M.; Bruce, D. W.; Davis, S. A.; Frost, R. M.; Hird, M. Chem. Commun. 2006, 1398-1400.

(67) Rangheard, C.; de Julian Fernandez, C.; Phua, P. H.; Hoorn, J.; Lefort, L.; de Vries, J. G. Dalton Trans. 2010, 39, 8464-8471.

(68) Rudenberg, H. G.; Rudenberg, P. G. In Adv. Imaging Electron Phys.; Peter, W. H., Ed.; Elsevier: 2010; Vol. Volume 160, p 207-286.

(69) Wang, Z. L. J. Phys. Chem. B 2000, 104, 1153-1175.

(70) Mueller, C.; Harb, M.; Dwyer, J. R.; Miller, R. J. D. J. Phys. Chem. Lett. 2013, 4, 2339-2347. 
(71) Riello, P.; Canton, P.; Benedetti, A. Langmuir 1998, 14, 6617-6619.

(72) Schmid, G. Chem. Rev. 1992, 92, 1709-1727.

(73) Aiken lii, J. D.; Finke, R. G. J. Mol. Catal. A: Chem. 1999, 145, 1-44.

(74) Jaska, C. A.; Manners, I. J. Am. Chem. Soc. 2004, 126, 1334-1335.

(75) Bayram, E.; Linehan, J. C.; Fulton, J. L.; Roberts, J. A. S.; Szymczak, N. K.; Smurthwaite, T. D.; Özkar, S.; Balasubramanian, M.; Finke, R. G. J. Am. Chem. Soc 2011, 133, 18889-18902.

(76) Zheng, H.; Sadtler, B.; Habenicht, C.; Freitag, B.; Alivisatos, A. P.; Kisielowski, C. Ultramicroscopy 2013, 134, 207-213.

(77) Kelsen, V.; Wendt, B.; Werkmeister, S.; Junge, K.; Beller, M.; Chaudret, B. Chem. Commun. 2013, 49, 3416-3418.

(78) Yan, J.-M.; Zhang, X.-B.; Han, S.; Shioyama, H.; Xu, Q. Angew. Chem. Int. Ed. 2008, 47, 2287-2289.

(79) Welther, A.; Bauer, M.; Mayer, M.; Jacobi von Wangelin, A. ChemCatChem 2012, 4, 1088-1093.

(80) Hudson, R.; Riviere, A.; Cirtiu, C. M.; Luska, K. L.; Moores, A. Chem. Commun. 2012, 48, 3360-3362.

(81) Sonnenberg, J. F.; Morris, R. H. ACS Catal. 2013, 3, 1092-1102.

(82) Jansat, S.; Gómez, M.; Philippot, K.; Muller, G.; Guiu, E.; Claver, C.; Castillón, S.; Chaudret, B. J. Am. Chem. Soc. 2004, 126, 1592-1593.

(83) Lin, Y.; Finke, R. G. J. Am. Chem. Soc 1994, 116, 8335-8353.

(84) Zhou, Q.; Wei, S.; Han, W. J. Org. Chem. 2014, 79, 1454-1460.

(85) Min, B. K.; Friend, C. M. Chem. Rev. 2007, 107, 2709-2724.

(86) Debouttière, P.-J.; Coppel, Y.; Denicourt-Nowicki, A.; Roucoux, A.; Chaudret, B.; Philippot, K. Eur. J. Inorg. Chem. 2012, 2012, 1229-1236.

(87) Wang, W.-N.; An, W.-J.; Ramalingam, B.; Mukherjee, S.; Niedzwiedzki, D. M.; Gangopadhyay, S.; Biswas, P. J. Am. Chem. Soc. 2012, 134, 11276-11281.

(88) Matsushita, T.; Shiraishi, Y.; Horiuchi, S.; Toshima, N. Bull. Chem. Soc. Jpn. 2007, 80, 1217-1225.

(89) Berne, B. J.; Pecora, R. Dynamic Light Scattering; 1st ed.; Wiley: New York, 1976.

(90) Crabtree, R. H.; Mellea, M. F.; Mihelcic, J. M.; Quirk, J. M. J. Am. Chem. Soc. 1982, 104, 107-113.

(91) Kaszuba, M.; McKnight, D.; Connah, M. T.; McNeil-Watson, F. K.; Nobbmann, U. J. Nanopart. Res. 2008, 10, 823-829.

(92) Wagner, C. D.; Naumkin, A. V.; Kraut-Vass, A.; Allison, J. W.; Powell, C. J.; John R. Rumble, J. In NIST Standard Reference Database 20; U.S. Department of Commerce: 2003; Vol. Version 3.5.

(93) Grosvenor, A. P.; Kobe, B. A.; Biesinger, M. C.; McIntyre, N. S. Surf. Interface Anal. 2004, 36, 15641574.

(94) Skomski, R. J. Phys. Condens. Matter 2003, 15, R841-R896.

(95) Batle, X.; Labarta, A. J. Phys. D.: Appl. Phys. 2002, 35, R15-R42.

(96) Dumestre, F.; Chaudret, B.; Amiens, C.; Renaud, P.; Fejes, P. Science 2004, 303, 821-823.

(97) Billas, I. M. L.; Becker, J. A.; Châtelain, A.; de Heer, W. A. Phys. Rev. Lett. 1993, 71, 4067-4070.

(98) Tiago, M. L.; Zhou, Y.; Alemany, M. M. G.; Saad, Y.; Chelikowsky, J. R. Phys. Rev. Lett. 2006, 97, 147202.

(99) Davies, I. W.; Matty, L.; Hughes, D. L.; Reider, P. J. J. Am. Chem. Soc. 2001, 123, 10139-10140.

(100) Campbell, E. J.; Zhou, H.; Nguyen, S. T. Org. Lett. 2001, 3, 2391-2393.

(101) Santini, R.; Griffith, M. C.; Qi, M. Tetrahedron Lett. 1998, 39, 8951-8954.

(102) Keifer, P. A.; Baltusis, L.; Rice, D. M.; Tymiak, A. A.; Shoolery, J. N. J. Magn. Reson., Ser. A 1996, 119, 65-75.

(103) Witham, C. A.; Huang, W.; Tsung, C.-K.; Kuhn, J. N.; Somorjai, G. A.; Toste, F. D. Nat. Chem. 2010, 2, 36-41.

(104) Collman, J. P.; Kosydar, K. M.; Bressan, M.; Lamanna, W.; Garrett, T. J. Am. Chem. Soc. 1984, 106, 2569-2579.

(105) Ahmadi, A.; Attard, G.; Feliu, J.; Rodes, A. Langmuir 1999, 15, 2420-2424. 
(106) Jansat, S.; Picurelli, D.; Pelzer, K.; Philippot, K.; Gomez, M.; Muller, G.; Lecante, P.; Chaudret, B. New J. Chem. 2006, 30, 115-122.

(107) Knoppe, S.; Dolamic, I.; Bürgi, T. J. Am. Chem. Soc. 2012, 134, 13114-13120.

(108) Knoppe, S.; Azoulay, R.; Dass, A.; Bürgi, T. J. Am. Chem. Soc. 2012, 134, 20302-20305.

(109) Knoppe, S.; Bürgi, T. Chimia 2013, 67, 236-239.

(110) Osawa, T. Chem. Lett. 1985, 1609-1612.

(111) Orito, Y.; Imai, S.; Niwa, S.; Nguyen, G. H. J. Synth. Org. Chem. Jpn. 1979, 37, 173-178.

(112) Orito, Y.; Imai, S.; Niwa, S. J. Chem. Soc. Jpn. 1979, 1118.

(113) Bönnemann, H.; Braun, G. A. Angew. Chem. Int. Ed. 1996, 35, 1992-1995.

(114) Baiker, A. J. Mol. Catal. A: Chem. 1997, 115, 473-493.

(115) Bonalumi, N.; Bürgi, T.; Baiker, A. J. Am. Chem. Soc. 2003, 125, 13342-13343.

(116) Maeda, N.; Hungerbühler, K.; Baiker, A. J. Am. Chem. Soc 2011, 133, 19567-19569.

(117) Ding, K.; Uozumi, Y. Handbook of Asymmetric Heterogeneous Catalysis; Wiley-VCH: Weinheim, 2008.

(118) Vos, D. D.; Vankelecom, I. F. J.; Jacobs, P. A. Chiral Catalyst Immobilization and Recycling; Wiley-VCH: Weinheim, 2000.

(119) Mallat, T.; Orglmeister, E.; Baiker, A. Chem. Rev. 2007, 107, 4863-4890.

(120) Demers-Carpentier, V.; Goubert, G.; Masini, F.; Lafleur-Lambert, R.; Dong, Y.; Lavoie, S.; Mahieu, G.; Boukouvalas, J.; Gao, H.; Rasmussen, A. M. H.; Ferrighi, L.; Pan, Y.; Hammer, B.; McBreen, P. H. Science 2011, 334, 776-780.

(121) Lázár, K. Hyperfine Interact. 2013, 217, 57-65.

(122) Joint Committee for Powder Diffraction Standards, The Mineral Powder Diffraction File (JCPDS); International Center for Diffraction Data: Swarthmore, Pennsylvania, 1997.

(123) Linn, D. E.; Guo, Y.; Cramer, S. P. Inorg. Chim. Acta. 2008, 361, 1552-1554.

(124) Bordiga, S.; Groppo, E.; Agostini, G.; van Bokhoven, J. A.; Lamberti, C. Chem. Rev. 2013, 113, 17361850.

(125) Bunker, G. Introduction to XAFS: A Practical Guide to X-ray Absorption Fine Structure Spectroscopy; Cambridge University Press: Cambridge UK, 2010. 